\title{
Plasma aromatase as a sensitive and selective potential biomarker of bladder cancer and its role in tumorigenesis
}

\author{
TOMASZ GUSZCZ ${ }^{1}$, BEATA SZYMAŃSKA ${ }^{2}$, ROBERT KOZLOWSKI ${ }^{1}$, \\ ZENON LUKASZEWSKI ${ }^{3}$, PAWEL LASKOWSKI ${ }^{4}$ and EWA GORODKIEWICZ ${ }^{2}$
}

\author{
${ }^{1}$ Department of Urology, J. Sniadecki Provincial Hospital of Białystok, 15-950 Białystok; ${ }^{2}$ Institute of Chemistry, \\ University of Białystok, 15-245 Białystok; ${ }^{3}$ Faculty of Chemical Technology, Poznan University of Technology, 60-965 Poznan; \\ ${ }^{4}$ Department of Human Anatomy, Medical University of Białystok, 15-230 Białystok, Poland
}

Received April 8,2019; Accepted September 26, 2019

DOI: $10.3892 / 01.2019 .11080$

\begin{abstract}
Bladder cancer (BCa) is the ninth most common cancer in the world and its early detection is crucial for successful therapy. Unfortunately, there are no satisfactory tools to detect $\mathrm{BCa}$ at early stages and $\mathrm{BCa}$ 's confirmation muscle-invasive. The search for a suitable biomarker is therefore necessary and aromatase is a potential candidate. The purpose of the current study was to determine if aromatase serves as a biomarker of BCa. A Surface Plasmon Resonance Imaging biosensor was applied for the quantification and determination of aromatase. A total of $3 \mu \mathrm{l}$ blood plasma was used for a single measurement. The results revealed that the aromatase concentration in the plasma of patients with $\mathrm{BCa}$ $(\mathrm{n}=78)$ ranged from $17.41-57.44 \mathrm{ng} / \mathrm{ml}$. The range determined in healthy donors $(\mathrm{n}=18)$ was $2.59-7.74 \mathrm{ng} / \mathrm{ml}$. Additionally, it was revealed that muscle invasive $\mathrm{BCa}$ samples exhibited elevated, statistically significant $(\mathrm{P}=0.01)$ average aromatase concentrations in blood plasma $(38.64 \mathrm{ng} / \mathrm{ml})$ when compared with non-muscle invasive samples $(29.83 \mathrm{ng} / \mathrm{ml})$. The results demonstrated that plasma aromatase may serve as an excellent bimarker of BCa with $100 \%$ sensitivity, $100 \%$ selectivity and an area under the curve value of the reciever operating characteristic curve equal to 1.0. Furthermore, the marker differenciated between muscle-invasive and non muscle-invasive $\mathrm{BCa}$ with a sensitivity of $60 \%$ and a specificity of $81 \%$. In conclusion, aromatase may serve a role in bladder tumorigenesis.
\end{abstract}

\section{Introduction}

Urinary bladder cancer $(\mathrm{BCa})$ is the ninth most common cancer worldwide. It is the fifth most common malignancy in males and

Correspondence to: Professor Ewa Gorodkiewicz, Institute of Chemistry, University of Bialystok, Ciolkowskiego 1K, 15-245 Bialystok, Poland

E-mail: ewka@uwb.edu.pl

Key words: aromatase, surface plasmon resonance imaging, biosensors, bladder cancer, liquid biopsy seventeenth most common in females with the global standardized incidence rate being 9/100,000 in males and 2/100,000 in females (1) Transitional cell carcinoma (TCC) is the predominant histologic type of $\mathrm{BCa}$ in the United States and Europe accounting for $90 \%$ of cases (2). Approximately $75 \%$ of BCas are diagnosed as superficial, confined to mucosa (Ta, TIS) and submucosa (T1) while $25 \%$ are muscle-invasive (T2-T4) (3). $\mathrm{BCa}$ remains a highly prevalent and lethal malignancy. The optimal treatment selection depends on early diagnosis as well as accurate staging and grading. Gender differences in $\mathrm{BCa}$ have been proposed to result from the influence of sex hormones (4-7). The search for cancer biomarkers in blood and urine is worthy of intense attention due to patients' comfort and ease of sampling. In general the expectation in respect to biomarkers is for their sensitivity and specificity to be as high as possible. Biomarkers have come to play an important role in routine clinical practice. They are seen as potential tools for the detection of and for the prediction of recurrence and progression of bladder carcinoma. Currently there is a need for new prognostic molecular biomarkers that can help clinicians to identify patients requiring early, aggressive treatment.

There are a dozen urinary biomarkers for $\mathrm{BCa}$ including the BCa stem-cell marker CD44 (8), the nuclear matrix protein 22 (NMP22) (9), the fibroblast growth factor receptor 3 (FGFR3) (9), the BCa-Specific Antigen-1 (BLCA-1) (10), cathepsin D (11), podoplanin (12), Cystatin C (13), BLCA-4, CYFRA 21-1 and Survivin (14). Several of them such as BLCA-1 (10), podoplanin (12) and Cystatin C (13) were also tested as blood serum biomarkers for BCa. Until now, however, none of the known urinary or serum biosensors exhibit satisfactory sensitivity and selectivity for successful diagnosis of BCa. The serum BLCA-1 marker is characterized by $74 \%$ sensitivity and $69 \%$ selectivity (10), the podoplanin serum biosensor shows $72 \%$ sensitivity and $69 \%$ selectivity (12) while Cystatin C displays $87 \%$ sensitivity and $92 \%$ selectivity (13). That is the reason that further research into finding new biomarkers for $\mathrm{BCa}$ is required. A recent publication of $\mathrm{Wu}$ et al (15) shows a high expression of aromatase in stroma associated with $\mathrm{BCa}$ and preliminary investigations confirmed that aromatase deserves our attention as a potential BCa biomarker.

Aromatase (known also as CYP19A1) is a key enzyme in the process of catalysis of androgens to estrogens. Raised 
levels of aromatase may result in an intramural microenvironment with increased estrogen production (15). Nguyen has reported that aromatase expression is correlated with bladder tumor pathological stage as well as poor survivability and has shown that the estrogen receptor may have a promoting role during tumorigenesis (16).

Aromatase is an enzymatic complex responsible for the biosynthesis of estrogens from androgens occurring in all speleids. This complex contains two different proteins: NADPH-cytochrome $\mathrm{P} 450$ reductase and cytochrome P450arom and is bound to the membrane of the endoplasmic reticulum of estrogen-producing cells via the N-terminal of the short, hydrophobic transmembrane domain (17). In humans aromatase is expressed in a number of cells such as the ovarian granular cells, the placental syncytiotrophoblast cells, Leydig cells, in skin fibroblasts and in many areas of the brain, including the hypothalamus, the hippocampus or the amygdala. Aromatase is also expressed in human adipose tissue. Increased expression of aromatase is critical in the pathology of such diseases as breast cancer, endometriosis or hypogonadism (18) while lack of or reduced activity of aromatase may cause reduced functioning of brain neurons and support the development of such diseases as Alzheimer's disease or Parkinson's disease. It has been scientifically proven that aromatase inhibitors (anastrozole, letrozole or exemestane) can be successfully used as drugs for hormone receptor breast cancer (19).

Aromatase activity can be measured through several methods. The enzyme-linked immunosorbent assay (ELISA) (20) has so far only been applied in tests for potential aromatase inhibitors. Other methods which deserve a mention include the mammalian cell bioassay and fluorescence substrate assay. Frequently the semi-quantitative immunohistochemical analysis is used, a method which additionally shows the location of aromatase in the tissue being investigated.

The concentration of aromatase in biological samples can also be measured using biosensors with surface plasmon resonance imaging (SPRi) detection with specific antibodies and inhibitors sensitive to Cytochrom P450arom used as receptors (11). Surface Plasmon Resonance Imaging (SPRi) is a sensitive, 'label-free' technique that can measure interactions between enzyme and inhibitor or antibody-antigen, which, in turn, can become a basis for the development of sensitive sensors for the determination of biologically active species $(21,22)$. SPRI biosensors can be used to study interactions in various biological systems containing proteins, oligonucleotides, oligosaccharides, lipids, phages, particles and virus cells (23) as well as for quantitative analysis (24,25). Recently this technique has gained significance in the resolution of various clinical problems.

The aim of this work was to investigate aromatase as a potential plasma BCa biomarker. The recently developed SPRi biosensor (11) selective for aromatase was applied. The method exhibits a linear response range of $0.3-5 \mathrm{ng} / \mathrm{ml}$, an LOD of $0.09 \mathrm{ng} / \mathrm{l}$ and an LOQ of $0.3 \mathrm{ng} / \mathrm{ml}$. The precision (RSD) is $1 \%$, and the recoveries of spikes in natural samples are within the range $98-103 \%$. Plasma samples corresponding to different stages of BCa were collected. Healthy donors' plasma samples were used as controls. There is no information concerning aromatase concentration in human blood but two other papers reported aromatase activity in human serum $(26,27)$.

\section{Materials and methods}

Reagents. Aromatase peptide and rabbit polyclonal antibody specific for aromatase (Lucerna-Chem AG, www.lucerna-chem.ch), cysteamine hydrochloride, N-ethyl-N'-(3-dimethylaminopropyl) carbodiimide (EDC; Sigma Steinheim), N-Hydroxysuccinimide (NHS) (Aldrich) were used. HBS-ES solution $\mathrm{pH}=7.4$ (0.01 M HEPES, $0.15 \mathrm{M}$ sodium chloride, $0.005 \%$ Tween $20,3 \mathrm{mM}$ EDTA), photopolimer ELPEMER SD 2054, hydrophobic protective paint SD 2368 UV SG-DG (Peters), Phosphate Buffered Saline (PBS) $\mathrm{pH}=7.4$, carbonate buffer $\mathrm{pH}=8.5$ (BIOMED) were used as received. Aqueous solutions were prepared with MilliQ water (Simplicity ${ }^{\circledR}$ MILLIPORE).

Patients. The samples were obtained from patients with TCC seeking treatment at the J. Sniadecki Provincial Hospital of Białystok (Białystok, Poland). The subjects were divided into two groups: malignant and control. Plasma samples of patients with initial (after cystoscopy) or confirmed (prior transurethral resection of bladder tumor-TURBT) diagnosis of BCa were obtained. Individuals diagnosed with additional malignant disease or endometriosis were excluded.

The control group included 18 healthy volunteers from the Blood Donor Centre of Białystok, Poland.

Cancer diagnosis was determined through a histological examination of tumor specimens obtained from transurethral resection or cystectomy. In the end the malignant group consisted of 78 patients with confirmed TCC. The clinical parameters including stage, grade, size, tendency to reoccur, pattern of growth and multifocal nature were determined. Patient clinical characteristics have been presented in Table I.

Approval (R-I-002/409/2014) for this study was obtained from the Bioethics Committee of the Medical University of Białystok (Białystok, Poland) with a written informed consent obtained from all the patients and donors.

Preparation of biological samples. Blood samples were obtained from patients' cubital vein. Plasma was prepared according to standard procedures. Plasma samples were frozen immediately and kept at $-80^{\circ} \mathrm{C}$. For the determination of aromatase concentration the prepared plasma samples were diluted tenfold with phosphate buffered saline (PBS).

Procedure determination of concentrations with SPRi biosensor

Chip preparation. Gold chips were manufactured as described in a previous paper $(28,29)$. The gold surface of the chip was covered with a photopolymer and hydrophobic paint, a procedure described in a previous paper $(28,29)$. 9x12 free gold surfaces were obtained. Through the use of this chip, nine different solutions can be simultaneously measured without mixing the tested solutions. Twelve single SPRi measurements can be performed from one solution.

Antibody immobilization. Chips were rinsed with ethanol and water and dried under a stream of argon. They were then immersed in $20 \mathrm{mM}$ cysteamine ethanolic solution for at least $2 \mathrm{~h}$ after which they were again rinsed with ethanol 
Table I. Demographic and clinicopathological characteristics of patients.

\begin{tabular}{lcc}
\hline Variable & Range & No. of patients \\
\hline Age (years) & $\leq 65$ & 34 \\
& $>65$ & 44 \\
Sex & Female & 23 \\
Tumor stage & Male & 55 \\
& Superficial (Ta+T1) & 34 \\
Tumor grade & Invasive (T2+T3+T4) & 44 \\
& Low grade & 37 \\
Tumor size (mm) & High grade & 41 \\
& $\leq 30$ & 38 \\
Recurrence & $>30$ & 40 \\
& Primary & 41 \\
Multiplicity & Recurrent & 29 \\
& Single & 44 \\
& Multiply & 34 \\
\hline
\end{tabular}

and water and dried under a stream of argon. The next step was the immobilization of the receptor. Antibody solution in a PBS buffer $(20 \mathrm{ng} / \mathrm{ml})$ was activated with NHS $(50 \mathrm{mM})$ and EDC $(200 \mathrm{mM})$ in a carbonate buffer $(\mathrm{pH}=8.5)$ environment. Then the activated receptor was placed on thiol (cysteamine) modified surface and incubated at $37^{\circ} \mathrm{C}$ for $1 \mathrm{~h}$.

SPRi measurements. SPRI measurements for the protein biosensor array were performed as described previously (29). The signal was measured twice on the basis of registered images, after the immobilization of the antibody and then after the interaction with aromatase. Plasma samples were placed directly on the prepared biosensor for $10 \mathrm{~min}$ to allow an interaction with the receptor. The volume of the sample applied to each measuring field was $3 \mu \mathrm{l}$. After this time the biosensor was washed with water to remove unbound molecules from the surface. The SPRi technique used during the study measured the signal at a constant angle of light. Two images were recorded: The first image reflects the immobilization of the antibody and the second image shows the interaction of aromatase with the sample containing the analyte. The SPRI signal, which is proportional to the conjugated biomolecules, was obtained through the subtraction of the signal before and after the interaction with the biomolecule for each site separately.

Statistical analysis. All results are given as the mean \pm standard error of the mean (SEM), calculated on the basis of 12 repeated measurements. Statistical analyses were performed using Student's t-test and $\mathrm{P}<0.05$ was considered to indicate a statistically significant difference. The receiver operating characteristic (ROC) curves with optimal cut-off points were calculated. Sensitivity, specificity, positive and negative predictive values were specified for cut-off points. All statistical analyses were performed using PQStat 1.6.4 Software.

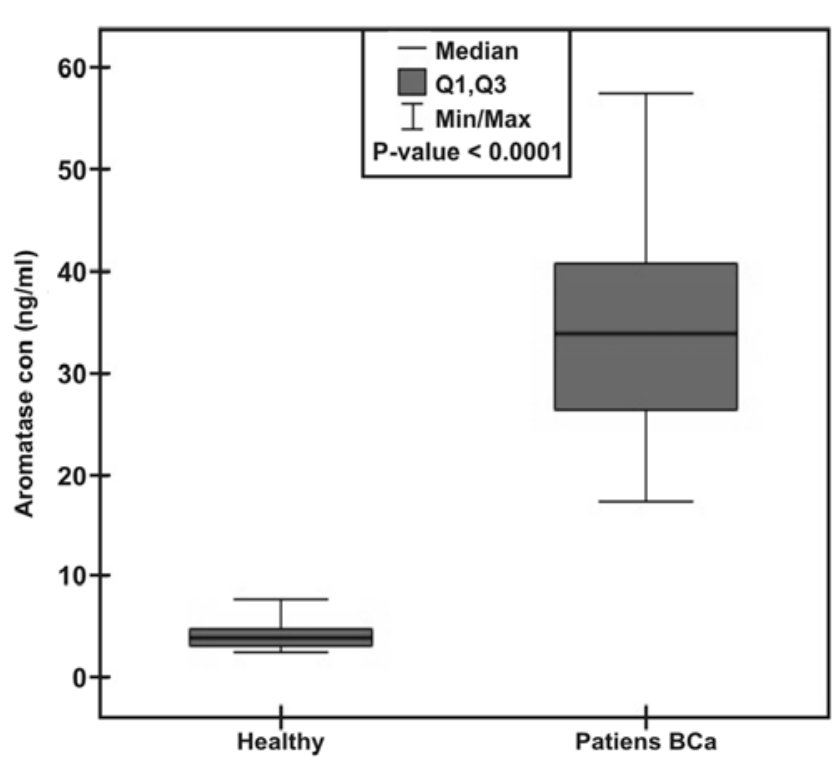

Figure 1. Box plots of aromatase blood plasma concentration in healthy individuals and patients with $\mathrm{BCa}$ tumors. $\mathrm{BCa}$, bladder cancer.

\section{Results}

Changes in aromatase concentration. A significant difference in plasma concentration of aromatase was observed between patients with $\mathrm{BCa}$ and healthy subjects. The aromatase concentration in plasma of $\mathrm{BCa}$ patients and healthy donors ranged from 17.41-57.44 and 2.59-7.74 $\mathrm{ng} / \mathrm{ml}$ respectively. The median value for healthy individuals reached 3.99 (an average of 4.3) while that of BCa patients amounted to 33.82 (an average of 33.98) (Fig. 1). This difference is highly statistically significant, with a P-value lower than 0.0001 .

Aromatase in terms of clinicopathological parameters of BCa. The aromatase concentration results were analyzed in terms of different cancer parameters with the following factors being considered: recurrence of the tumor, tumor stage, tumor grade, size and multiply of the tumor. Table II shows the plasma concentration of the aromatase in correlation to clinicopathological characteristics.

The aromatase concentration in plasma of non muscle-invasive and muscle-invasive patients fit within the range of 17.41-46.78 and 20.64-57.44 ng/ml, respectively (Fig. 2). The median for non muscle-invasive patients was $29.83 \mathrm{ng} / \mathrm{ml}$ (an average of 31.19) and that of muscle-invasive BCa patients was calculated at $38.64 \mathrm{ng} / \mathrm{ml}$ (an average of 37.53). This difference is statistically significant, with a P-value of 0.01 .

ROC analysis. ROC curve analysis was performed and demonstrated that blood plasma aromatase levels could be used to distinguish patients with bladder tumor from healthy individuals through the area under the curve of 1 $(\mathrm{P}=0.0001)$. Specificity, sensitivity, positive predictive value (PPV) and negative predictive value (NPV) was estimated at $100 \%$ (Fig. 3). Furthermore, the level of plasma aromatase was able to distinguish patients with muscle invasive tumors from patients with non muscle-invasive tumors through the area under the curve of $0.7(\mathrm{P}=0.0012)$. Other parameter values 
Table II. Diagnostic characteristics of plasma aromatase concentration ratios compared with various clinocopathological parameters.

Concentration of aromatase $[\mathrm{ng} / \mathrm{ml}]$

Parameters

Range

Median

P-value

\section{Primary/recurrent}

Primary $(n=41)$

Recurrent ( $\mathrm{n}=29)$

$19.62-57.44$

34.06

0.14

Multiplicity

Single $(\mathrm{n}=44)$

$17.41-56.81$

33.17

20.64-57.44

35.55

$\begin{array}{ll}17.41-46.78 & 30.05\end{array}$

Multiply ( $n=34)$

$17.41-46.78$

29.83

20.64-57.44

38.64

Muscle invasive $(\mathrm{n}=44) \quad(\mathrm{T} 2+\mathrm{T} 3=\mathrm{T} 4)$

$19.62-57.44$

30.8

$17.41-56.81$

34.01

High-grade (41)

20.64-46.75

35.71

17.41-57.44

32.53

Size $(\mathrm{mm})$

$>30(\mathrm{n}=40)$

$17.41-57.44$

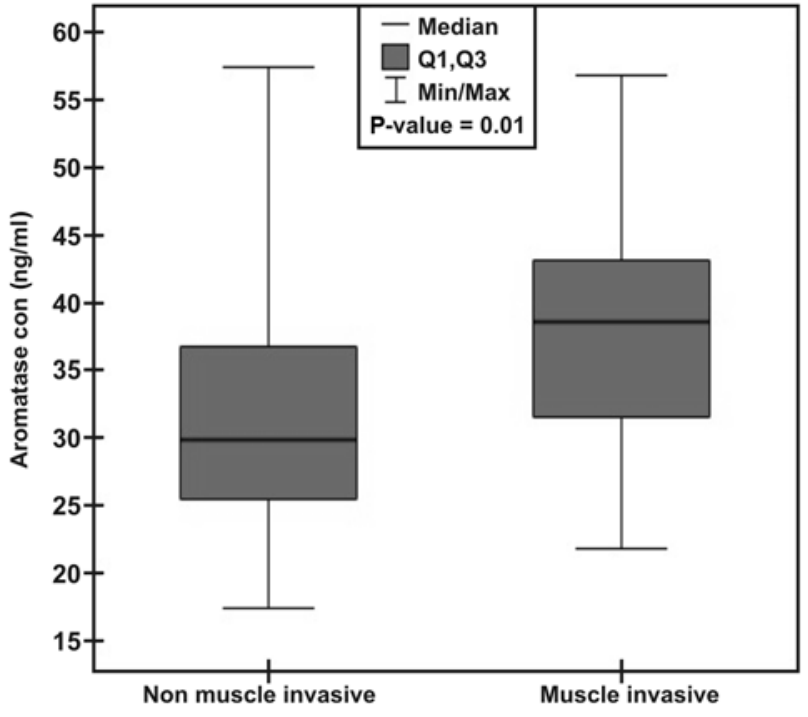

Figure 2. Box plots of aromatase blood plasma concentration in non muscle-invasive and muscle-invasive tumors.

were as follows: sensitivity- $60 \%$, specificity $81 \%$, PPV $74 \%$ and NPV 70\% (Fig. 4).

\section{Discussion}

The obtained results are surprisingly good. The values for the average and the median for aromatase plasma concentration for patients with $\mathrm{BCa}$ are almost 10 times higher than the corresponding values for healthy individuals. The gap between the lowest result for BCa patients $(17.41 \mathrm{ng} / \mathrm{ml})$ and the highest result from the set of results for healthy individuals $(7.74 \mathrm{ng} / \mathrm{ml})$ is almost $10 \mathrm{ng} / \mathrm{ml}$ and there are

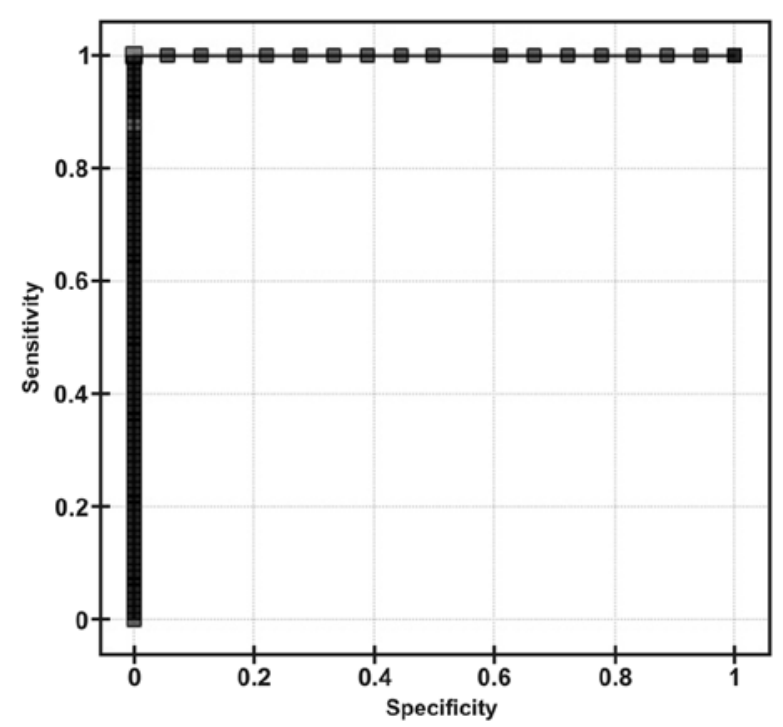

Figure 3. Receiver operating characteristic curve of blood plasma aromatase concentrations for healthy individuals and patients with $\mathrm{BCa}$. Cut-off value, $17.41 \mathrm{ng} / \mathrm{ml}$. BCa, bladder cancer.

no overlapping results within these two groups (Fig. 1). The difference is highly statistically significant, with a $\mathrm{P}$-value lower than 0.0001 . Thus, plasma aromatase as the BCa marker exhibits $100 \%$ sensitivity and $100 \%$ selectivity and the AUC of the ROC curve is 1.0 (Fig. 3). The cut-off value concentration calculated from the ROC curves is equal to $17.41 \mathrm{ng} / \mathrm{ml}$. Results above this value should be considered as positive for TCC. This type of result is rare not only for BCa markers but also in general. The other studied potential blood BCa markers (BLCA-1, podoplanin, cystatin C) exhibited $72-87 \%$ sensitivity and $69-92 \%$ 


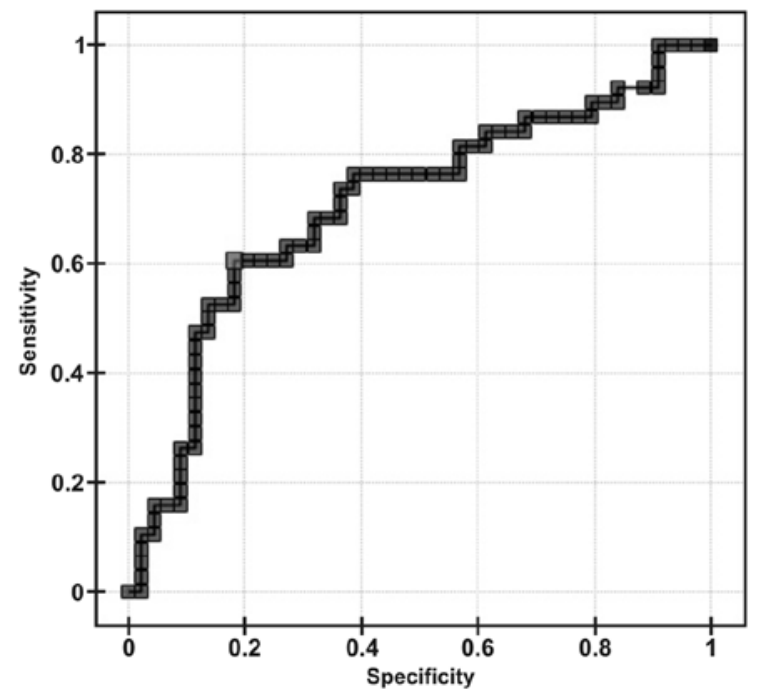

Figure 4. Receiver operating characteristic curve of plasma aromatase concentrations for patients with muscle-invasive and non muscle-invasive $\mathrm{BCa}$. Cut-off value, $37.32 \mathrm{ng} / \mathrm{ml}$. BCa, bladder cancer.

specificity $(10,12,13)$. In terms of sensitivity and selectivity plasma aromatase also produces better results than urinary BCa markers.

It is certainly true that further studies into aromatase as a BCa marker may discover problems with the use of this substance as a marker. Particularly the range of aromatase blood concentration for individuals not suffering from $\mathrm{BCa}$ may vary due to different factors such as the difference in aromatase activity due to coronary arterial disease (27).

Certainly, significantly more non-cancer blood samples are needed to test the real potential of aromatase as a marker, including a decision curve analysis. This is a limitation to the present study. The authors hope that this paper will encourage other groups to carry out such investigations. However, the obtained results are a very good starting point for the recommendation of aromatase as a BCa marker. An introduction of plasma aromatase as a $\mathrm{BCa}$ marker may significantly improve early diagnosis of this disease. It is worth mentioning that the use of the level of aromatase concentration in blood (plasma) for this purpose presented in this paper is the first such data ever published.

The plasma aromatase concentration may also be useful in the determination of muscle-invasiveness of BCa. Statistically, muscle-invasive tumors have significantly higher concentrations of aromatase $(P-v a l u e=0.01)$ in comparison to non-muscle invasive cancers with their sensitivity reaching $60 \%$ and their specificity being $81 \%$. Thus, the results for non-muscle and for muscle invasive cancer partly overlap (Fig. 2) but the higher the aromatase concentration the higher the probability of muscle invasiveness of BCa. The cut-off value concentration calculated from the ROC curve is equal to $37.31 \mathrm{ng} / \mathrm{ml}$. Patients with aromatase concentrations above this value should be considered as having bladder invasive TCC, subject to a sensitivity of $60 \%$ and a specificity of $81 \%$.

Aromatase expression was found to be high in epithelial and stroma tissue of $\mathrm{BCa}$ and was associated with worse overall survival rate (15). These results are consistent with those reported in this paper. High aromatase expression was found in endometrial cancer but conflicting findings were presented for prostate cancer where aromatase overexpression demonstrates a protective effect (30). This suggests that sex hormones have a different influence on particular cancers' biology (31).

Generally, hormones may play an important role in BCa. Epidemiological differences between males and females (3) suggest potential involvement of sex hormones in tumorigenesis and progression of $\mathrm{BCa}$ (32). Men are 3 to 4 times more often afflicted by $\mathrm{BCa}$ (2) even after chemical influence and cigarette smoking are taken into consideration (33). Females are diagnosed more frequently with a more progressive stage of the disease and display poorer treatment results after cystectomy and a higher risk of disease reoccurrence in comparison to males, a fact that may be explained by earlier invasion and progression. Moreover, it has been proven that estrogen, estrogen receptor, testosterone and dihydrotestosteron (34-36) as well as androgen receptor (37) are involved in $\mathrm{BCa}$ development. It has been reported that loss of androgen receptor expression was correlated with the progression of BCa stage (5). Interdependence between hormone receptors and aromatase observed in case of breast cancer $(38,39)$ may also be a significant factor in $\mathrm{BCa}$ development.

According to Kirma et al (39) aromatase may directly contribute to tumorigenesis by paracrine elevation of estrogen what leads to the induction of genes involved in cell cycle and down-regulation of tumor suppressor genes altering their mutual relationships and increasing cellular proliferation. This is consistent with the findings of Tekmal and Santen (40) who observed that local estrogen synthesis via aromatase in breast tissue could be important in the initiation of breast cancer as well as for its progression.

Thus, apart from advancing the proposal of a new $\mathrm{BCa}$ biomarker our results may also introduce a new factor in understanding BCa biology. It should be pointed out that this paper provides initial data concerning aromatase concentration in blood plasma, although the enzyme may be present in various tissues, including adipose.

Finally, it is worth stressing the significance of the introduction of the SPRi technique into the set of tools used in the investigation of cancer biomarkers. A limited number of reliable methods available for the determination of cancer biomarkers in body fluids is a significant barrier in the faster development of so called liquid biopsy. The SPRi technique is label-free, relatively inexpensive, operationally simple, sufficiently accurate and precise and the results of this paper have confirmed its potential within this area.

In conclusion, plasma aromatase may serve as an excellent biomarker of BCa with $100 \%$ sensitivity, $100 \%$ selectivity and an AUC value of the ROC curve equal to 1.0. Additionally, levels of plasma aromatase distinguish between muscle-invasive and non muscle-invasive BCa with a sensitivity of $60 \%$ and a specificity of $81 \%$. The present study also determined the concentration of aromatase present in the plasma of healthy individuals and patients with BCa.

\section{Acknowledgements}

Not applicable. 


\section{Funding}

The present study received financial support from the Polish Ministry of Science and Higher Education under subsidy for maintaining the research potential of the Faculty of Biol-Chem, University of Białystok (grant no. 162/2018).

\section{Availability of data and materials}

The datasets used and/or analysed during the present study are available from the corresponding author on reasonable request.

\section{Authors' contributions}

TG, EG, ZL conceived the current study. TG, EG and BS designed the current study. BS performed the experiments. TG collected plasma samples. TG, EG, BS, RK, PL and $\mathrm{ZL}$ acquired, analyzed and interpreted the data, drafted the manuscript and approved the final manuscript for publication. TG, EG, RK, ZL, BS and PL agree to be accountable for all aspects of the work in ensuring that questions related to the accuracy or integrity of any part of the work are appropriately investigated and resolved.

\section{Ethics approval and consent to participate}

Ethical approval for the current study was obtained from the Bioethics Committee of the Medical University of Białystok (Białystok, Poland; approval no. R-I-002/409/2014). Written informed consent was obtained from all patients and donors.

\section{Patient consent for publication}

Not applicable.

\section{Competing interests}

The authors declare that they have no competing interests.

\section{References}

1. Ferlay J, Soerjomataram I, Dikshit R, Eser S, Mathers C, Rebelo M, Parkin DM, Forman D and Bray F: Cancer incidence and mortality worldwide: Sources, methods and major patterns in GLOBOCAN 2012. Int J Cancer 136: E359-E386, 2015.

2. Siegel R, Ma J and Zou Z: Cancer statistics, 2014. Cancer J Clinic 64: 9-29, 2014

3. Burger M, Catto JW, Dalbagni G, Grossman HB, Herr H, Karakiewicz P, Kassouf W, Kiemeney LA, La Vecchia C, Shariat S and Lotan Y: Epidemiology and risk factors of urothelial bladder cancer. Eur Urol 63: 234-241, 2013.

4. Imada S, Akaza H, Ami Y, Koiso K, Ideyama Y and Takenaka T: Promoting effects and mechanisms of action of androgen in bladder carcinogenesis in male rats. Eur Urol 31: 360-364, 1997.

5. Boorjian S, Ugras S, Mongan NP, Gudas LJ, You X, Tickoo SK and Scherr DS: Androgen receptor expression is inversely correlated with pathologic tumor stage in bladder cancer. Urology 64: 383-388, 2004.

6. Miyamoto H, Yao JL, Chaux A, Zheng Y, Hsu I, Izumi K, Chang C, Messing EM, Netto GJ and Yeh S: Expression of androgen and oestrogen receptors and its prognostic significance in urothelial neoplasm of the urinary bladder. BJU Int 109: 1716-1726, 2012.

7. Kauffman EC, Robinson BD, Downes M, Marcinkiewicz K, Vourganti S, Scherr DS, Gudas LJ and Mongan NP: Estrogen receptor- $\beta$ expression and pharmacological targeting in bladder cancer. Oncol Rep 30: 131-138, 2013.
8. Azevedo R, Soares J, Gaiteiro C, Peixoto A, Lima L, Ferreira D, Relvas-Santos M, Fernandes E, Tavares A, Cotton S, et al: Glycan affinity magnetic nanoplatforms for urinary glycobiomarkers discovery in bladder cancer. Talanta 184: 347-355, 2018.

9. Bangma CH, Loeb S, Busstra M, Zhu X, El Bouazzaoui S, Refos J, Van Der Keur KA, Tjin S, Franken CG, Van Leenders GJ, et al: Outcomes of a bladder cancer screening program using home hematuria testing and molecular markers. Eur Urol 64: 41-47, 2013.

10. Wang Z, Li H, Chi Q, Qui Y, Li X and Xin L: Clinical significance of serological and urological levels of bladder cancer-specific antigen-1 (BLCA-1) in bladder cancer. Med Sci Monit 24: 3882-3887, 2018.

11. Gorodkiewicz E, Sankiewicz A and Laudanski P: Surface plasmon resonance imaging biosensors for aromatase based on a potent inhibitor and a specific antibody: Sensor development and application for biological material. Cent Eur J Chem 12: 557-567, 2014.

12. Sankiewicz A, Guszcz T, Mena-Hortelano R, Zukowski K and Gorodkiewicz E: Podoplanin serum and urine concentration in transitional bladder cancer. Cancer Biomark 16: 343-350, 2016.

13. Tokarzewicz A, Guszcz T, Onopiuk A, Kozlowski R and Gorodkiewicz E: Utility of cystatin $\mathrm{C}$ as a potential bladder tumour biomarker confirmed by surface plasmon resonance technique. Indian J Med Res 21: 846-850, 2018.

14. Vrooman OP and Witjes JA: Urinary markers in bladder cancer. Eur Urol 53: 909-916, 2008.

15. Wu S, Ye J, Wang Z, Lin SX, Lu M, Liang Y, Zhu X, Olumi AF, Zhong W and Wu CL: Expression of aromatase in tumor related stroma is associated with human bladder cancer progression. Cancer Biol Ther 19: 175-180, 2018.

16. Nguyen DP, O'Malley P, Al Hussein Al Awamlh B, Furrer MA, Mongan NP, Robinson BD, Wang GJ and Scherr DS: Association of aromatase with bladder cancer stage and long-term survival: New insights into the hormonal paradigm in bladder cancer. Clin Genitourin Canc 15: 256-262.e1, 2017.

17. Carreau S, Lambard S, Delaland C, Denis-Galeraud I, Bilinska B and Bourguiba S: Aromatase expression and role of estrogens in male gonad: A review. Reprod Biol Endocrin 1: 35, 2003.

18. Miedlich SU, Karamooz N and Hammes SR: Aromatase deficiency in a male patient-case report and review of the literature. Bone 93: 181-186, 2016.

19. Miller WR: Aromatase inhibitors: Mechanism of action and role in the treatment of breast cancer. Semin Oncol 30 (4 Suppl 14): S3-S11, 2003.

20. Satoh K, Nonaka R, Ishikawa F, Ogata A and Nagai F: In vitro screening assay for detecting aromatase activity using rat ovarian microsomes and estrone ELISA. Biol Pharm Bull 31: 357-362, 2008.

21. Gorodkiewicz E: The surface plasmon resonance imaging sensor for papain based on immobilized cystatin. Protein Pept Lett 14: 443-445, 2007.

22. Gorodkiewicz E, Guszcz T, Roszkowska-Jakimiec W and Kozlowski R: Cathepsin D serum and urine concentration in superficial and invasive transitional bladder cancer as determined by surface plasmon resonance imaging. Oncol Let 8: 1323-1327, 2014.

23. Thevenot DR, Toth K, Durst RA and Wilson GS: Electrochemical biosensors: Recommended definition and classification. Pure Appl Chem 71: 2333-2348, 1999.

24. Laudanski P, Gorodkiewicz E, Ramotowska B, Charkiewicz R, Kuzmicki M and Szamotowicz J: Determination of cathepsins $\mathrm{B}, \mathrm{D}$ and $\mathrm{G}$ concentration in eutopic proliferative endometrium of women with endometriosis by the surface plasmon resonance imaging (SPRI) technique. Eur J Obstet Gynecol Reprod Bio 169: 80-83, 2013.

25. Gorodkiewicz E and Luszczyn J: Surface plasmon resonance imaging (SPRI) sensor for cystatin determination based on immobilized papain. Protein Pept Lett 18: 23-29, 2011.

26. Dhefer IH, Abbas SAR and Ahmed NSH: Polymorphism of cytochrome $\mathrm{p} 450$, superfamily 19 , polypeptide 1 gene and related to aromatase enzyme activity in acromegaly Iraqi patients. Asian J Pharm Clin Res 10: 228-232, 2017.

27. Meng Y, Adi D, Wu Y, Wang Y, Abudoukelimu M, Huang D, Ma X, Liu C, Wang T, Liu F, et al: CYP19A1 polymorphisms associated with coronary artery disease and circulating sex hormone levels in a Chinese population. Oncotarget 8: 97101-97113, 2017.

28. Gorodkiewicz E: Surface plasmon resonance imaging sensor for cathepsin determination based on immobilized cystatin. Protein Pept Lett 16: 1379-1385, 2009.

29. Gorodkiewicz E, Regulska E and Roszkowska-Jakimiec W: Determination of the active form concentration of cathepsins D and B by SPRI biosensors. J Lab Diagn 46: 107-109, 2010. 
30. Grindstad T, Skjefstad K, Andersen S, Ness N, Nordby Y, Al-Saad S, Fismen S, Donnem T, Khanehkenari MR, Busund LT, et al: Estrogen receptors $\alpha$ and $\beta$ and aromatase as independent predictors for prostate cancer outcome. Sci Rep 6: 33114, 2016.

31. Chang C, Lee SO, Yeh S and Chang TM: Androgen receptor (AR) differential roles in hormone-related tumors including prostate, bladder, kidney, lung, breast and liver. Oncogene 33: 3225-3234, 2014.

32. Guilherme G, Gakis G, Smith CL and Fahmy O: Effects of androgen and estrogen receptor signaling pathways on bladder cancer initiation and progression. Bladder Cancer 2: 127-137, 2016.

33. Castelao JE, Yuan JM, Skipper PL, Tannenbaum SR, Dado-Dominguez M, Crowder JS, Ross RK and Yu MC: Gender-and smoking-related bladder cancer risk. J Natl Cancer Inst 93: 538-545, 2001.

34. Shen SS, Smith CL, Hsieh JT, Yu J, Kim IY, Jian W, Sonpavde G, Ayala GE, Younes M and Lerner SP: Expression of estrogen receptors-alpha and -beta in bladder cancer cell lines and human bladder tumor tissue. Cancer 106: 2610-2616, 2006.

35. Kawahara T, Ide H, Kashiwagi E, El-Shishtawy KA, Li Y, Reis LO, Zheng Y and Miyamoto $\mathrm{H}$ : Enzalutamide inhibits androgen receptor-positive bladder cancer cell growth. Urol Oncol 34: 432.e15-e23, 2016.
36. Liu X, Cheng X, Liu X, He L, Zhang W, Wang Y, Sun W and Ji Z: Investigation of the urinary metabolic variations and the application in bladder cancer biomarker discovery. Int J Cancer 143: 408-418, 2018.

37. Miyamoto H, Yang Z, Chen YT, Ishiguro H, Uemura H, Kubota Y, Nagashima Y, Chang YJ, Hu YC, Tsai MY, et al: Promotion of bladder cancer development and progression by androgen receptor signals. J Natl Cancer Inst 99: 558-568, 2007.

38. Kinoshita Y and Chen S: Induction of aromatase (CYP19) expression in breast cancer cells through a nongenomic action of estrogen receptor alpha. Cancer Res 63: 3546-3555, 2003.

39. Kirma N, Gill K, Mandava U and Tekmal RR: Overexpression of aromatase leads to hyperplasia and changes in the expression of genes involved in apoptosis, cell cycle, growth, and tumor suppressor functions in the mammary glands of transgenic mice. Cancer Res 61: 1910-1918, 2001.

40. Tekmal RR and Santen RJ: 'Local estrogen production: Is aromatase an oncogene?' In: Manni A (ed), Contemporary Endocrinology: Endocrinology of Breast Cancer. Humana Press, Totowa, NY, pp79-89, 1999. 